Volume 5

\title{
Reducing Interpersonal Discrimination for Pregnant Job Applicants Seeking Professional Jobs
}

\author{
Sarah Singletary Walker \\ Creighton University \\ Whitney Botsford Morgan \\ University of Houston-Downtown
}

Follow this and additional works at: https://scholarworks.bgsu.edu/pad

Part of the Human Resources Management Commons, Industrial and Organizational Psychology Commons, and the Other Psychology Commons

How does access to this work benefit you? Let us know!

\section{Recommended Citation}

Singletary Walker, Sarah and Botsford Morgan, Whitney (2019) "Reducing Interpersonal Discrimination for Pregnant Job Applicants Seeking Professional Jobs," Personnel Assessment and Decisions: Number 5 : Iss. 2 , Article 5.

DOI: https://doi.org/10.25035/pad.2019.02.005

Available at: https://scholarworks.bgsu.edu/pad/vol5/iss2/5

This Main Article is brought to you for free and open access by the Journals at ScholarWorks@BGSU. It has been accepted for inclusion in Personnel Assessment and Decisions by an authorized editor of ScholarWorks@BGSU. 


\title{
REDUCING INTERPERSONAL DISCRIMINATION for Pregnant Job Applicants Seeking PROFESSIONAL Jobs
}

\section{Sarah Singletary Walker ${ }^{1}$ and Whitney Botsford Morgan ${ }^{2}$}

\author{
1. Department of Marketing and Management, Creighton University \\ 2. Department of Management and Insurance \& Risk Management, University of Houston \\ - Downtown
}

\begin{abstract}
KEYWORDS
pregnancy, job applicant, counterstereotypic information, individuation
\end{abstract}

\section{.}

\section{.}

This study seeks to extend previous research on the experiences of pregnant job applicants from retail settings (see Botsford Morgan, Walker, Hebl, \& King, 2013) to entry-level professional jobs. The current research utilized a 2 (expectant status: not pregnant, pregnant) x 4 (counterstereotypic information: control, competence, commitment, flexibility) betweensubjects factorial design to empirically test the relative efficacy of real, practical interventions designed to reduce the interpersonal discrimination (enhanced negativity and reduced positivity) that pregnant women may encounter when applying for entry-level professional jobs. Results reveal that pregnant job applicants experience more positive interactions when presenting information about their competence than when they say nothing. This study extends our understanding of manifestations of bias and its reduction with regard to pregnant workers applying for entry-level professional jobs.

-

Women represent approximately $47 \%$ of the U.S. workforce, of which $70 \%$ are mothers with children under 18 years of age (DeWolf, 2017). Moreover, two out of three mothers $(66 \%)$ worked during pregnancy, with $56 \%$ of pregnant workers remaining in full-time roles (U.S. Census Bureau, 2015). Mothers have made considerable strides with respect to their overall participation in the labor force; in fact, "mothers are the primary or sole earners for 40 percent of households with children under 18 today, compared with 11 percent in 1960" (DeWolf, 2017). Despite these gains and federal law protecting pregnant workers (e.g., Pregnancy Discrimination Act, 1978), pregnancy discrimination persists. For instance, women in every industry report pregnancy discrimination (National Partnership for Women \& Families, 2016). According to the National Partnership for Women and Families (2016), approximately $12 \%$ of charges of pregnancy discrimination derive from discriminatory terms and conditions of employment, suggesting the presence of pregnancy bias from the onset of a women's search for employment.

A large body of research examines the conditions and processes that support gender discrimination in the workplace (see Heilman \& Caleo, 2018); however, much of the previous research on discrimination in the hiring context focuses on issues impacting women in general. For instance, recent research reveals women are more likely to receive guarded recommendations for hire than men (Madera, Hebl, Dial, Martin, \& Valian, 2018). Moreover, in STEM (science, technology, engineering, and mathematics) related professions, women experience significantly greater amounts of discrimination in the selection process (Funk \& Parker, 2018). Likewise, previous research reveals that when candidates have identical traits and abilities, men are more likely to be recommended for hire than women (Coffman, Exley, \& Niederle, 2017). An understudied explanation for these disparities stems from the fact that many women undergo a transition from worker to mother during their careers. In effect, pregnant women have unique stigma and specific experiences that are related to their expectant status (Jones et al., 2016; King \& Botsford, 2009), which may contribute to differential experiences gaining entry to, and within, the workplace.

There is limited but important research examining the specific experiences that pregnant women encounter when trying to gain entry to organizations. First, through an experimental field study, Hebl and colleagues (Hebl, King,

Corresponding author:

Sarah Singletary Walker

Creighton University, Heider College of Business

Department of Marketing and Management

2500 California Plaza, Omaha, NE 68178

Email: sarahwalker1@creighton.edu 
Glick, Singletary, \& Kazama, 2007) revealed that pregnant job applicants experience more interpersonal negativity than their non-pregnant counterparts. Second, a paper-people study revealed that, counter to its hypotheses, pregnant workers were rated warmer and more competent, while simultaneously experiencing discrimination (i.e., lower salary and hiring recommendations) more than nonpregnant candidates (Masser, Grass \& Nesic, 2007). Third, Botsford Morgan, Singletary Walker, Hebl, and King (2013) conducted a field study examining the experiences of pregnant women applying for retail jobs and, importantly, tested the relative efficacy of proposed interventions to reduce discrimination in a hiring context. Results revealed that compared to nonpregnant applicants, pregnant job applicants received differential treatment in the form of increased amounts of negative interpersonal displays. In addition, the researchers also examined mechanisms to reduce such displays for pregnant women seeking retail jobs. Providing individuating information as a strategy designed to counteract stereotypes resulted in less negative interactions for the pregnant job applicants. Specifically, when hiring managers in a retail context received counterstereotypical information to combat the perceived lack of commitment and inflexibility, they displayed less interpersonal discrimination toward pregnant job applicants.

According to the National Partnership for Women \& Families (2016) approximately 14\% of charges of pregnancy discrimination occur in retail settings which affects approximately $11 \%$ of the U.S. workforce. Thus, an examination of pregnant workers in retail settings provides a first step toward understanding how pregnant women might utilize compensatory strategies within a specific job context. However, it is not clear whether these findings apply in other job domains, specifically, for knowledge workers in other positions (e.g., professional jobs) and industries (e.g., health care, finance). It is important to consider other employment contexts or industries, as data from the Department of Labor's Women's Bureau (2013) indicates that approximately $30 \%$ of women are employed in sales and office occupations whereas $42 \%$ of women are employed in management and professional occupations. Given that women are employed in professional jobs at higher rates than retail occupations, it is important to consider the effectiveness of remediation mechanisms in other workplace contexts. The current study is largely a replication of Botsford Morgan et al. (2013); however, it also extends previous research on the experiences of pregnant job applicants by empirically testing the relative efficacy of real, practical interventions designed to reduce the differential treatment, including increased negative and reduced positive behaviors, that pregnant women may encounter when applying for knowledge jobs as opposed to retail jobs.

\section{Manifestations of Bias}

Seminal work by Hebl and colleagues established a typology for differential treatment that we utilize to understand the bias experienced by pregnant women (Hebl, Foster, Mannix, \& Dovidio, 2002). Specifically, a series of studies distinguished between two disparate forms of discrimination consisting of formal (i.e., overt forms of discrimination that may consist of denying individuals access to employment and assistance in a sales context) and interpersonal discrimination (Hebl et al., 2002). Formal discrimination is defined as overt, illegal forms of differential treatment that prevents access to jobs, information, and even perhaps equitable compensation. In effect, as a result of one's membership in a marginalized group, an individual receives negative, job-related outcomes. Conversely, interpersonal discrimination is defined as differences that emerge during ongoing interactions that occur as a result of one's marginalized status. Specifically, interpersonal discrimination is characterized by both increased amounts of negativity (e.g., hostility, rudeness, frowning) and decreased amounts of positivity (e.g., smiling, eye contact, affirmative gestures). A series of field studies demonstrate that members of a variety of marginalized groups (e.g., assumed homosexuals, obese individuals, Muslims job applicants, pregnant women) do not report experiences of formal discrimination (i.e., equally likely to be hired, assisted, provided information) at rates that differ from nonmarginalized individuals. However, individuals from marginalized groups do report experiencing greater amounts of interpersonal discrimination than their nonmarginalized counterpart (Botsford Morgan et al., 2013; Hebl et al., 2002; Hebl et al., 2007; King \& Ahmad, 2010; King, Shapiro, Hebl, Singletary, \& Turner, 2006). Specifically, the series of studies find that marginalized individuals experience differential treatment in the form of both receiving significantly more negative, interpersonal behaviors and simultaneously experiencing interactions that contain fewer amounts of positive behaviors than their non-marginalized counterparts (Hebl et al., 2007; King et al., 2006; Singletary \& Hebl, 2009). Of particular relevance to the current study is a finding that pregnant job applicants experience interactions that are marked by increased amounts of negative, interpersonal behaviors compared to their nonpregnant counterparts (Botsford Morgan et al., 2013; Hebl et al., 2007). However, as mentioned previously, the extant field studies in this area were conducted in shopping malls with applicants seeking customer service jobs in retail establishments. Consonant with this line of research on interpersonal discrimination, the current research examines both enhanced negativity and reduced positivity toward pregnant applicants seeking professional jobs. Given the null findings in previous studies regarding formal discrimination, we focus our attention on 
interpersonal discrimination. That is, similar to previous research, we anticipate the presence of interpersonal discrimination (i.e., enhanced negativity and reduced positivity) for pregnant women applying for entry-level professional jobs.

Hypothesis 1a: Pregnant job applicants will experience more negative behaviors than their nonpregnant counterparts.

Hypothesis 1b: Pregnant job applicants will experience less positive behaviors than their nonpregnant counterparts.

\section{Reducing Subtle Bias}

Theoretical and empirical research suggests that when perceivers have access to individuating information about stigmatized targets, they are less likely to display biases toward such individuals (Fiske \& Neuberg, 1990; Kunda \& Williams, 1993; Miller \& Kaiser, 2001). Previous research suggests that the provision of counterstereotypic information may be the most effective approach for reducing bias (Blair \& Banaji, 1996; Rubinstein, Jussim, \& Stevens, 2018; Rudman, Glick, \& Phelan, 2008). For example, several research studies found that participants who were (versus were not) exposed to counterstereotypic exemplars during a training session were less likely to express prejudice and discriminatory behaviors toward targets (Dasgupta \& Greenwald, 2001; Kawakami, Dovidio, Moll, Hermsen, \& Russin, 2000; Richeson \& Ambady, 2001; Stone \& Moskowitz, 2011). The extant research in organizational contexts reveals that individuals (e.g., managers and store personnel) who receive counterstereotypic information about job applicants and customers behave both more positively and less negatively than those who do not receive such information (e.g., Botsford Morgan et al., 2013; King et al., 2006; Singletary \& Hebl, 2009). Organizations interested in decreasing employment discrimination can use this stream of research as a basis for developing interventions designed to educate employees, managers, and/or senior leadership about counterstereotypic features of individuals in stigmatized groups (see Sabat, Lindsey, King, \& Jones, 2016). Though it is important to consider organizational-level interventions, the current study examines an individual-level intervention that may be used in real hiring settings (i.e., job/career fairs).

\section{Stereotypes and Counterstereotypic Interventions}

Previous research reveals that there are a number of stereotypes that may negatively impact the perceptions of pregnant women and mothers in job settings. Botsford Morgan et al., (2013) examined four remediation mechanisms designed to target potentially problematic stereotypes about pregnant employees: (a) incompetence, (b) lack of commitment, (c) inflexibility, and (d) need for accommodating expectant mothers in the workplace. Interestingly, not all forms of counterstereotypic information reduced interpersonal discrimination. Specifically, receiving information that a pregnant job applicant was competent or would not require an accommodation did not reduce the hostility displayed toward pregnant applicants. The authors posited that these results may have been attributable to the jobs being in retail settings and suggested that additional research is needed to determine the extent to which the results are applicable in other job domains (Botsford Morgan et al., 2013).

We anticipate that the effectiveness of the remediation strategies (i.e., counterstereotypic information) for knowledge jobs may vary from those of retail jobs. Specifically, contrary to the findings for retail jobs, we anticipate that competence may be a particularly important characteristic for professional jobs. For instance, professional jobs often require relevant education, training, and experience as indicators of one's ability (in this case, competence) to complete the required job tasks. Thus, pregnant women who provide information about their competence may counteract perceptions of incompetence that are typically assumed about pregnant women (Cuddy, Fiske \& Glick, 2004). Conversely, in line with the findings from retail settings, we anticipate that one's commitment to the organization may also be a desired characteristic for prospective employment. Organizations invest considerable resources to acquire talent, and as such organizations may be particularly focused on seeking employees who are likely to remain with an organization for a significant amount of time (Frank, Finnegan, \& Taylor, 2004). Given that pregnant women are assumed to have a greater focus on their families than careers (Bragger, Kutcher, Morgan, \& Firth, 2002), we anticipate that providing information about one's commitment may reduce the emergence of stereotypes regarding pregnant women's lack of commitment. Likewise, we anticipate that flexibility or one's ability to transition to a new job will also be relevant for professional jobs. Presently, organizations report a shortage of talent and a need to staff their organizations quickly (Harrison \& Raice, 2018). This is particularly true in the United States, which has one of the world's shortest timeframes from application to hire in the world with a hiring delay of 23.8 days (Chamberlain, 2015). Given the changing nature of jobs and current demands for skilled employees, it may be important that individuals have the ability to begin working quickly. Given that each of these three characteristics (i.e., competence, commitment, flexibility) is particularly relevant to organizations, we anticipate that providing such individuating information to organizational employees may serve as mechanisms that thwarts the activation of stereotypes related to pregnant women. We do not anticipate that the need for an accommodation (or lack thereof) will have an impact on the experiences of pregnant women seeking entry-level professional jobs. Accommoda- 
tion, as studied in Botsford Morgan et al. (2013), tested the stereotype by enacting a script focused on health insurance and benefits coverage. Although this script was relevant in the retail setting, we do not believe this holds for entry-level professional jobs where benefits are frequently provided as a normative part of the employment agreement. In other words, any mention of not requiring health insurance and/ or other benefits is not applicable to recruiters of professional-level (i.e., salaried) jobs and therefore will not impact ratings of the job applicant.

In summary, the current research largely replicates Botsford Morgan et al. (2013) by drawing upon individuation theory (Fiske \& Neuberg, 1990) and testing the relative efficacy of counterstereoptyic information (Blair \& Banaji, 1996) through three perceptual mechanisms that may drive interpersonal discrimination toward pregnant job applicants (incompetence, lack of commitment, and inflexibility) seeking entry-level professional jobs.

Hypothesis 2a: Pregnant job applicants will experience fewer negative behaviors when they provide counterstereotypic information about their competence, commitment, and flexibility than when they say nothing.

Hypothesis 2b: Pregnant job applicants will experience more positive behaviors when they provide counterstereotypic information about their competence, commitment, and flexibility than when they say nothing.

\section{METHOD}

\section{Participating Organizations}

Organizations seeking to recruit entry-level employees (e.g., recent college graduate or graduate students) at career fairs open to the public in a major metropolitan area were selected for inclusion in the study. A total of 150 organizations were selected for inclusion in the current study. Organizations ranged in size from small (less than $25 \mathrm{em}-$ ployees) to large (100,000+ employees). In addition, participating organizations represented a wide range of industries (e.g., healthcare, commercial [i.e., wholesale] retail, oilfield services, telecommunications, insurance sales, education).

\section{Procedure}

Six female confederate job applicants, who were blind to the study's hypotheses, attended career or job fairs in a major metropolitan area and were randomly assigned to interact with an organizational representative (e.g., recruiter) and enact a standardized script. Confederates in the study wore standardized attire (e.g., professional-looking suit, wedding band), carried and provided copies of a standardized résumé, and enacted one of four scripts that con- tained the informational manipulation (see below for actual scripts) when interacting with organizational recruiters. At the completion of each interaction with an organizational recruiter, confederates completed a paper-and-pencil questionnaire that contained items assessing interpersonal discrimination and provided information about their experience in each interaction.

Training. Prior to beginning the study, confederates completed training in an effort to standardize each interaction. During training, confederates rehearsed the scripts in order to demonstrate memorization of each of the scripts. In addition, confederates participated in role plays with the researchers who assumed the role of organizational recruiter and asked questions to enable the confederates to become familiar with possible follow-up questions and answers from recruiters. In an effort to standardize the interaction as much as possible, confederates were instructed to use information that was contained on a standardized resume when answering experience-related questions from recruiters.

Expectant status (pregnancy) manipulation. The expectant status of the confederate was manipulated through the use of a pregnancy prosthesis using methodology identical to that found in previous field studies examining pregnancy discrimination (e.g., Hebl et al., 2007). Specifically, in half the conditions, the confederate wore a pregnancy prosthetic that was designed to make the individual appear to be approximately 6 months pregnant, and in the other half no prosthetic was worn. Regardless of "expectant status," all confederates wore standardized professional attire consisting of dark pants, collared shirt, and a blazer.

Counterstereotypic information (strategy) manipulation. The scripts that confederates enacted were developed in line with Botsford Morgan et al. (2013) and were modified slightly for appropriateness in a career fair setting.

Control condition. Confederates approached recruiters and were instructed to: (a) introduce themselves, (b) explain that they are interested in an entry-level position, (c) ask the recruiter to identify specific jobs that are available, (d) ask about the job tasks associated with one of the jobs for which the organization is hiring, and (e) leave their resume. During training, confederates memorized the following script: "Hello, my name is I am interested in an entry-level position. What are the specific jobs that you are hiring for? What specifically might a do? IF they have not asked already: Here's a copy of my resume."

Competence. Interactions for this condition contained the same five elements as the control condition. In addition to the control condition, confederates made a standardized statement to indicate that they were fully capable. Similar to Botsford Morgan et al. (2013), confederates enacted a script that included the following statements, "You may be wondering why I am applying for a position. I have work experience. I was educated at a local university ${ }^{1}$, and I'm 
pretty competent. I am confident I can handle a new challenge."

Commitment. Interactions in this condition were designed to include each of the elements in the control condition and also to include statements affirming one's commitment to work. A standardized script was developed to ensure the recruiter that the confederate would be committed to the organization, specifically, confederates enacted a script in line with Botsford Morgan et al., (2013) that included the following statements, "You may be wondering why I am applying for a position. I am an extremely dedicated person who is willing to put in the work required to get the job done. People have always said one of my greatest strengths is my commitment to my work."

Flexibility. In line with Botsford Morgan et al. (2013), we developed a standardized script to demonstrate that the confederate was available to begin employment immediately and had no time constraints with respect to working hours; specifically, confederates enacted a script that included the following statements, "You may be wondering why I am applying for this position. My schedule is flexible. I have the help I need so I can work whenever you need me."

Measures of interpersonal discrimination. We conducted a principal components factor analysis with a varimax rotation restricting the analysis to two factors. Factor $1($ Eigenvalue $=9.86$; variance accounted for $=54.80 \%)$ included seven items. The items included rudeness (.75), purse lips (.74), furrow brows (.71), hostility (.81), awkward (.72), nervous (.65), and standoffishness (.68). The items that loaded onto Factor 1 formed the Negative Behavioral Outcomes scale $(\alpha=.90)$. One item (end the interaction) was eliminated because it did not load onto the factor. Factor 2 (Eigenvalue $=1.55$; variance accounted for $=8.6 \%$ ) included eight items. The factor consisted of items examiningfriendliness (.75), smiling (.71), helpful (.76), interest (.78), nodding (.66), comfort (.81), enthusiasm (.79), and paying attention (.62). Two items examining positivity (i.e., interpersonal distance and eye contact) did not load onto either factor and were eliminated. The items that loaded onto Factor 2 formed the Positive Behavioral Outcomes scale ( $\alpha$ $=.93$ ).

Negative behavioral outcomes. A seven-item composite was created as an indicator of the recruiter's negative behavioral responses to the confederate job applicant. Confederate job applicants provided ratings that evaluated the extent to which the recruiter was (a) rude, (b) pursing their lips, (c) furrowing their eyebrows, (d) hostile, (e) awkward, (f) nervous, and (g) standoffish, $\alpha=.90$.

Positive behavioral outcomes. An eight-item composite was created as an indicator of the amount of positive be-

1 A well-regarded university name was used in the script; however, it is removed in order to maintain confidentiality. haviors exhibited by recruiters during the interaction. Confederates evaluated the extent to which the recruiter was (a) friendly, (b) nodding, (c) smiling, (d) helpful, (e) interested, (f) comfortable, (g) enthusiasm, and (h) paying attention, $\alpha$ $=.93$.

\section{RESULTS}

In the current study, confederate job applicants engaged in a total of 177 interactions with individuals from 150 different organizations. A group of six demographically diverse (Asian, Black, Hispanic, and White) undergraduate and graduate students served as confederate job applicants in the study. Confederates provided demographic information about organizational representatives for $82.7 \%$ of the interactions. Confederates reported $47.1 \%$ of recruiters were male and $52.9 \%$ female. We conducted preliminary analyses to determine the presence of confederate effects. Results from a MANOVA on negative and positive behavioral outcomes revealed a significant confederate effect, $F(2,142)=6.25, p<.01, \eta^{2}=.08$. Thus, in the remaining MANOVA analyses, we utilize a covariate to control for confederate effects.

In Hypothesis 1, we predicted that, when not enacting scripts which contain counter-stereotypical information (i.e., control condition), pregnant job applicants would experience more negative (H1a) and fewer positive behavioral outcomes $(\mathrm{H} 1 \mathrm{~b})$ than their non-pregnant counterparts. We conducted a series of $t$-tests to examine if the interpersonal treatment received by job applicants varied as a function of expectant status. Contrary to expectations, results revealed that pregnant and nonpregnant job applicants experienced similar levels of negative, $t(38)=-.31, p=.78$, and positive behavioral outcomes, $t(38)=.73, p=.49$ (see Table 1 for means and standard deviations). Thus, results do not support our hypotheses that pregnant job applicants experience more negative behaviors (H1a) and fewer positive behaviors (H1b) compared to their nonpregnant counterparts when in the control condition.

To examine Hypothesis 2, we conducted a four-way MANOVA on negative and positive behavioral outcomes to examine the hypotheses of interest. Specifically, in Hypothesis 2 , we anticipated that providing counterstereotypic information (i.e., scripts involving competence, commitment, flexibility) would result in fewer amounts of negative behaviors (H2a) while simultaneously involving increased amounts of positive behaviors (H2b). The omnibus MANOVA yielded significant results for the main effect of counterstereotypic information, $F(6,152)=5.38, p<.001, \eta^{2}=$ .18 , on the outcomes of interest. Moreover, the univariate results revealed significant effects of counterstereotypic information on both positive, $F(3,76)=7.19, p=.002, \eta^{2}$ $=.18$, and negative, $F(3,76)=5.04, p=.001, \eta^{2}=.19$, behavioral outcomes. Planned comparisons revealed that, 
compared to the pregnant control condition $(M=3.82, S D$ $=1.27)$, providing information about one's competence $(M$ $=4.76, S D=1.33$ ) resulted in greater amounts of positive behavioral outcomes, $t(44)=-2.44, p=.02$. In addition, compared to the pregnant control condition $(M=0.63, S D$ $=0.72$ ), providing information about one's flexibility $(M$ $=0.06, S D=0.09$ ) resulted in fewer reports of negative behavioral outcomes when interacting with recruiters, $t(36)$ $=-3.61, p=.003$. Thus, results provide partial support for both Hypothesis $2 \mathrm{a}$ and Hypothesis $2 \mathrm{~b}$.

We conducted an exploratory analysis to examine the extent to which providing counterstereotypic information has an impact on the interpersonal treatment experienced by pregnant as well as nonpregnant women. The exploratory analyses utilized a 2 (expectant status: not pregnant, pregnant) by 4 (counterstereotypic information: control, competence, commitment, flexibility) between-subjects factorial design. The omnibus MANOVA revealed significant results for expectant status, $F(2,167)=4.16, p=.02$, $\eta^{2}=.05$, countersteotypic information, $F(6,336)=4.22, p$ $<.001, \eta^{2}=.07$, as well as a significant expectant status by counterstereotypic information interaction, $F(6,336)=5.31$, $p<.001, \eta^{2}=.09$. An examination of the between subjects effects revealed nonsignificant main effects of expectant status on negative behavioral outcomes, $F(1,168)=2.16, p$ $=.15, \eta^{2}=.00$ and positive behavioral outcomes, $F(1,168)$ $=0.40, p=.53, \eta^{2}=.01$ as a result of expectant status. The between-subjects effects for counterstereotypic information revealed a different pattern. That is, a significant effect of counterstereotypic information emerged for negative behavioral outcomes, $F(3,168)=7.43, p<.001, \eta^{2}=.12$, but not for positive behavioral outcomes, $F(3,168)=2.17, p=.09$, $\eta^{2}=.04$. Post hoc $t$-tests with Bonferroni corrections revealed that there were significant differences in the amount of negative behavioral outcomes reported by job applicants when utilizing scripts involving competence, $t(91)=-2.26$, $p=.03$, and flexibility, $t(85)=-3.06, p=.003$, when compared to those using scripts involving commitment (see Table 1 for means and standard deviations). Last, the expectant status by strategy interaction yielded significant effects on positive behavioral outcomes, $F(3,168)=3.99, p=.01$, $\eta^{2}=.07$, but not on the negative behavioral outcomes, $F(3$, $168)=1.85, p=.14, \eta^{2}=.03$. Results from the subsequent post-hoc tests with Bonferroni corrections revealed that pregnant women who sought entry-level professional jobs had interactions that were marked by greater amounts of positivity, $t(48)=2.91, p=.01$, when they provided counterstereotypic information regarding their competence $(M=$ 4.76; $S D=1.32$; see Table 1 for complete results) compared to nonpregnant women who provided information about their competence $(M=3.68, S D=1.29)$. Figure 1 demonstrates that pregnant women who used a strategy involving competence had interactions that were marked by significantly greater amounts of positivity than non-pregnant women who enacted an identical script, as well as pregnant women who made counterstereotypic verbalizations involving commitment, flexibility, or no strategy.

\section{DISCUSSION}

The current research is largely a replication of Botsford Morgan et al. (2013), however, current findings extend our understanding of mechanisms (i.e., provision of counterstereotypic information) that remediate bias toward pregnant job applicants seeking entry-level, professional roles. Unexpectedly, and unlike previous research in retail establishments (Botsford Morgan et al., 2013; Hebl et al., 2007), in the control condition, pregnant and nonpregnant women

TABLE 1.

Descriptive Statistics for Counterstereotypical Information Conditions as a Function of Expectant Status

\begin{tabular}{|c|c|c|c|c|}
\hline Outcomes & Control & Competence & Commitment & Flexibility \\
\hline \multicolumn{5}{|c|}{ Negative behavioral outcomes } \\
\hline Pregnant & $\begin{array}{c}0.63(0.72) \\
n=21\end{array}$ & $\begin{array}{c}0.36(1.12) \\
n=25\end{array}$ & $\begin{array}{c}0.87(1.44) \\
n=18\end{array}$ & $\begin{array}{c}0.06(0.08) \\
n=17\end{array}$ \\
\hline Nonpregnant & $\begin{array}{c}0.56(0.65) \\
n=19\end{array}$ & $\begin{array}{c}0.74(0.84) \\
n=25\end{array}$ & $\begin{array}{c}1.20(0.98) \\
n=25\end{array}$ & $\begin{array}{c}0.67(0.73) \\
n=27\end{array}$ \\
\hline \multicolumn{5}{|c|}{ Negative behavioral outcomes } \\
\hline Pregnant & $\begin{array}{c}3.82(1.27) \\
n=21\end{array}$ & $\begin{array}{c}4.76(1.33) \\
n=25\end{array}$ & $\begin{array}{c}3.51(1.26) \\
n=18\end{array}$ & $\begin{array}{c}3.74(0.93) \\
n=17\end{array}$ \\
\hline Nonpregnant & $\begin{array}{c}4.19(1.15) \\
n=19\end{array}$ & $\begin{array}{c}3.68(1.30) \\
n=25\end{array}$ & $\begin{array}{c}3.78(1.29) \\
n=25\end{array}$ & $\begin{array}{c}4.20(1.25) \\
n=27\end{array}$ \\
\hline
\end{tabular}




\section{FIGURE 1 .}

Interaction results for 2 (Expectant Status: Pregnant, Nonpregnant) by 4 (Counterstereotypical Information: Control, Competence, Commitment, Flexibility) MANOVA

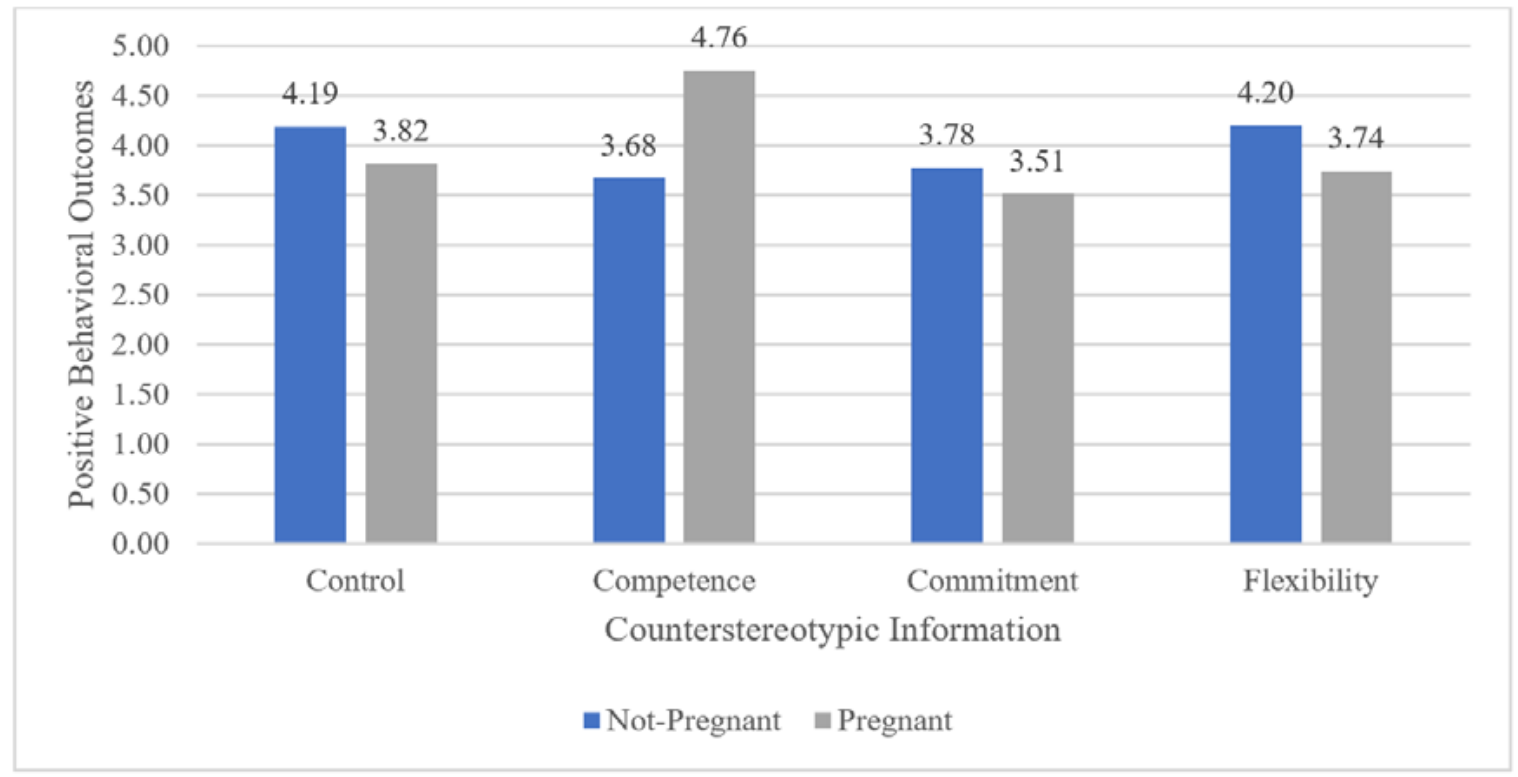

experienced similar levels of negative (H1a) and positive (H1b) behaviors from organizational recruiters. We posit that this may be the result of the training that recruiters receive that results in a greater awareness of the importance of remaining neutral in their interactions with prospective hires (Grensing-Pophal, 2018), particularly interactions that involve members of protected classes.

The findings from this study extend the literature on remediation mechanisms by examining the relative efficacy of counterstereotypic information that pregnant women may utilize when applying for entry-level professional jobs. Specifically, we reveal that the presentation of information about one's competence (i.e., job applicant's educational degree) resulted in more favorable interactions $(\mathrm{H} 2 \mathrm{~b})$ between job applicants and recruiters compared to when pregnant job applicants said nothing to counteract stereotypes. In addition, the presentation of information regarding one's flexibility resulted in significantly less negative behavioral outcomes compared to the control condition (H2a). This is interesting as it suggests the presentation of information about one's educational background and flexibility to begin working is more effective than presenting no information. Coupled with previous research, the current results suggest that the individuation strategy to utilize varies as a function of the type of job that one is seeking. Previous research examining jobs in retail establishments (see Botsford Morgan et al., 2013) found that commitment and flexibility were particularly useful for reducing interpersonal discrimination. We posit that this finding may be attributable to the job demands (e.g., high turnover context, operating hours range from early in the morning to the nighttime - outside the traditional work hours) inherent in such positions. In contrast, for entry-level professional jobs that seek knowledge workers, as shown in the current research, we argue that competence is seen as an important job characteristic. Thus, unlike in the retail establishment context, targeting the stereotypes associated with competency was effective at increasing the overall positivity within the interactions. This finding suggests that competence (or lack thereof) may be a particularly salient stereotype for professional jobs, and therefore important that pregnant job applicants may consider highlighting this competency when attempting to gain entry to professional roles.

Interestingly, the exploratory analyses reveal that pregnant job applicants who engage in a counterstereotypic information strategy that exudes competence have more positive interactions with recruiters than nonpregnant job applicants who present information regarding their competence. It is also interesting to note, and discuss, that nonpregnant job applicants did not receive the same "boost" or positive interactions with recruiters when they engaged in the competence strategy. In effect, in this study, the provision of counterstereotypic information related to competence was uniquely beneficial (i.e., results in more positive 
interactions) for pregnant women in the current study.

We look to shifting standards to explain this exploratory finding (Masser et al., 2007). Previous research examining vignettes reveals that pregnant women are perceived as lacking competence and that such perceptions may inform selection decisions (Cuddy, Fiske, \& Glick, 2004). Thus, we posit that the standards for demonstrating competence would vary by expectant status. Specifically, we anticipate that the threshold for competence might be lower for pregnant job applicants. Our findings are in line with the shifting standards literature (Biernat \& Manis, 1994). Specifically, in this study, the same statements regarding competence were made by both pregnant applicants and nonpregnant applicants. However, pregnant applicants reported experiencing significantly more positive behavioral outcomes than their nonpregnant counterparts who enacted the same competence script. The behavioral indicators suggest that the provision of counterstereotypical (i.e., competence) information enabled the pregnant applicant to be seen as more than a stereotypical representative of a marginalized group (Kunda \& Thagard, 1996; Rubinstein, Jussim, \& Stevens, 2018). Thus, due to a shifting standard, findings from this study suggest that, specifically for pregnant applicants, the provision of information about one's competence resulted in more positive interactions for pregnant as opposed to non-pregnant applicants, which may in turn influence one's ultimate entry into an organization. In summary, these results reinforce previous research that targeting stereotypes associated with pregnancy, specifically competence, results in more favorable interpersonal interactions for pregnant job applicants. This finding provides guidance for pregnant job applicants on a real, practical intervention that may be enacted in order to facilitate entry to entry-level professional jobs.

\section{Limitations and Future Research}

Although this study is a first step toward understanding the mechanisms by which pregnant workers can remediate experienced discrimination when applying for professional jobs it is not without its limitations. Namely, it is important to note that the job/career fairs in this study were targeted toward entry-level roles. Future research is needed to determine whether pregnant women in middle to upper-level professional jobs have similar experiences when searching for employment. In addition, given the nature of the experimental field study where the organizations were blind to their "participation" it limits the types of information collected about the organization. Refined information about the jobs or organizations would allow for finer grained explanations for strategies that may be effective for certain roles in organizations and/or across industries. Given the findings of this research have promise future research could expand the scale to expand the depth and breadth of participating organizations.

\section{Conclusion}

The current study extends our understanding of manifestations of bias and its reduction with regard to pregnant women applying for entry-level professional jobs. Moreover, the research broadens our understanding of remediation strategies by providing evidence for the importance of organizational context when determining appropriate strategies to employ when seeking employment. Specifically, pregnant job applicants should target job relevant stereotypes in order to engage in more favorable interactions with organizational representatives.

\section{REFERENCES}

Biernat, M., \& Manis, M. (1994). Shifting standards and stereotype-based judgments. Journal of personality and social psychology, 66(1), 5.

Blair, I. V., \& Banaji, M. (1996). Automatic and controlled processes in stereotype priming. Journal of Personality and Social Psychology, 70, 1142-1163. doi: 10.1037/00223514.70.6.1142

Botsford Morgan, W., Walker, S. S., Hebl, M. M. R., \& King, E. B. (2013). A field experiment: Reducing interpersonal discrimination toward pregnant job applicants. Journal of Applied Psychology, 98(5), 799-809.

Bragger, J. D., Kutcher, E., Morgan, J., \& Firth, P. (2002). The effects of the structured interview on reducing biases against pregnant job applicants. Sex Roles, 46, 215-226. doi: 10.1023/ A:1019967231059

Chamberlain, A. (2015). Why Is Hiring Taking Longer?. New Insights from Glassdoor Data. Glassdoor.

Coffman, K. B., Exley, C. L., \& Niederle, M. (2017). When gender discrimination is not about gender. Harvard Business School Working Paper, No. 18-504.

Cuddy, A., Fiske, S. T., \& Glick, P. (2004). When professionals become mothers warmth doesn't cut the ice. Journal of Social Issues, 60, 701-718.

Dasgupta, N., \& Greenwald, A. G. (2001). On the malleability of automatic attitudes: Combating automatic prejudice with images of admired and disliked individuals. Journal of Personality and Social Psychology, 81, 828-841. doi: 10.1037/0022-3514.81.5.800

DeWolf, M. (2017). 12 Stats about working women. U.S. Department of Labor Blog. Retrieved from: https://blog.dol.gov /2017/03/01/12-stats-about-working-women

Fiske, S. T., \& Neuberg, S. L. 1990. A continuum of impression formation, from category-based to individuating processes: Influences of information and motivation on attention and interpretation. In M. P. Zanna (Ed.), Advances in experimental social psychology (Vol. 23, pp. 1-74). New York, NY: Academic Press.

Frank, F. D., Finnegan, R. P., \& Taylor, C. R. (2004). The race for talent: Retaining and engaging workers in the 21 st century. Human Resource Planning, 27, 12-25. 
Funk, C. \& Parker, K. (2018). Women and men in STEM often at odds over workplace equity. Pew Research Center Report. Retrieved from http://www.pewsocialtrends. org/2018/01/09/women-and-men-in-stem-often-at-oddsover-workplace-equity/

Grensing-Pophal, L. (2018). Are you inadvertently turning off job candidates. Society for Human Resource Magazine. Retrieved from: https://www.shrm.org/resourcesandtools/ hr-topics/talent-acquisition/pages/are-you-turning-off-jobcandidates.aspx

Harrison, D., \& Raice, S. (2018). How bad is the labor shortage? Cities will pay you to move there. Wall Street Journal, retrieved from: https://www.wsj.com/articles/howbad-is-the-labor-shortage-cities-will-pay-you-to-movethere-1525102030

Hebl, M. R., Foster, J. B., Mannix, L. M. \& Dovidio, J. F. (2002). Formal and interpersonal discrimination: A field study of bias toward homosexual applicants. Personality and Social Psychology Bulletin, 28, 815-825. doi: $10.1177 / 0146167202289010$

Hebl, M. R., King, E. B., Glick, P., Singletary, S. L. \& Kazama, S. (2007). Hostile and benevolent reactions toward pregnant women: Complementary interpersonal punishments and rewards that maintain traditional roles. Journal of Applied Psychology, 92, 1499-1511. doi: 10.1037/0021-9010.92.6.1499

Heilman, M., \& Caleo, S. (2018). Gender discrimination in the workplace. In A. Collela, \& E. King (Eds.), The Oxford handbook of workplace discrimination. New York, NY: Oxford University Press.

Jones, K. P., King, E. B., Gilrane, V. L., McCausland, T. C., Cortina, J. M., \& Grimm, K. J. (2016). The baby bump: Managing a dynamic stigma over time. Journal of Management, OnlineFirst. DOI: 10.1177/0149206313503012

Kawakami, K., Dovidio, J. F., Moll, J., Hermsen, S., \& Russin, A. (2000). Just say no (to stereotyping): Effects of training in the negation of stereotypic associations on stereotype activation. Journal of Personality and Social Psychology, 78, 871-888. doi: 10.1037/0022-3514.78.5.871

King, E. B., \& Ahmad, A. S. (2010). An experimental field study of interpersonal discrimination toward Muslim job applicants. Personnel Psychology, 63(4), 881-906.

King, E. B., \& Botsford, W. E. (2009). Managing pregnancy disclosures: Understanding and overcoming the challenges of expectant motherhood at work. Human Resource Management Review, 19, 314-323.

King, E. B., Shapiro, J., Hebl, M. R., Singletary, S. L., \& Turner, S. L. (2006). The stigma of obesity in customer service: A mechanism for remediation and bottom-line consequences of interpersonal discrimination. Journal of Applied Psychology, 91, 579-593. doi: 10.1037/0021-9010.91.3.579

Kunda, Z., \& Thagard, P. (1996). Forming impressions from stereotypes, traits, and behaviors: A parallel-constraint-satisfaction theory. Psychological Review, 103, 284-308.

Kunda, Z., \& Sherman Williams, B. (1993). Stereotypes and construal of individuating information. Personality and Social Psychology Bulletin, 19, 90-99. doi: $10.1177 / 0146167293191010$

Madera, J. M., Hebl, M. R., Dial, H., Martin, R., \& Valian, V. (2018). Raising doubts in letters of recommendation for academia:
Gender differences and their impact. Journal of Business and Psychology, OnlineFirst.

Masser, B., Grass, K., \& Nesic, M. (2007). We like you, but we don't want you: The impact of pregnancy in the workplace. Sex Roles, 57, 703-712.

Miller, C. T., \& Kaiser, C. R. (2001). A theoretical perspective on coping with stigma. Journal of Social Issues, 57, 73-92. doi: 10.1111/0022-4537.00202

National Partnership for Women \& Families. (2016, October). By the numbers: Women continue to face pregnancy discrimination in the workplace. An analysis of U.S. Equal Employment Opportunity Commission Charges (Fiscal Years 20112015). Retrieved from http://www.nationalpartnership.org/ research-library/workplace-fairness/pregnancy-discrimination/by-the-numbers-women-continue-to-face-pregnancy-discrimination-in-the-workplace.pdf.

Richeson, J. A., \& Ambady, N. (2001). Who's in charge? Effects of situational roles on automatic gender bias. Sex Roles, 44, 493-512. doi: 10.1023/A:1012242123824

Rubinstein, R. S., Jussim, L., \& Stevens, S. T. (2018). Reliance on individuating information and stereotypes in implicit and explicit person perception. Journal of Experimental Social Psychology, 75, 54-70.

Rudman, L. A., Glick, P., \& Phelan, J. E. (2008). From the laboratory to the bench: Gender stereotyping research in the courtroom. In E. Borgida \& S. T. Fiske (Eds.), Beyond common sense: Psychological science in the courtroom (pp. 83-102). Malden, MA: Blackwell.

Sabat, I. E., Lindsey, A. P., King, E. B., \& Jones, K. P. (2016). Understanding and overcoming challenges faced by working mothers: A theoretical and empirical review. In C. Spitzmueller, \& R. A. Matthews (Eds.), Research perspectives on work and the transition to motherhood (pp. 9-31). Cham, Switzerland: Springer.

Singletary, S. L., \& Hebl, M. R. (2009). Compensatory strategies for reducing interpersonal discrimination: The effectiveness of acknowledgments, increased positivity, and individuating information. Journal of Applied Psychology, 94(3), 797.

Stone, J., \& Moskowitz, G. B. (2011). Non-conscious bias in medical decision-making: What can be done to reduce it? Medical Education, 45, 768-775, doi.org/10.1111/j.13652923.2011.04026.x.

U.S. Census Bureau. (2015). First-time mothers at work. Now and then: How first-time mothers have changed their employment. Income and program participation survey. Retrieved from: https://www.dol.gov/wb/FirstTimeMothers-508-July2015REV.pdf

U.S. Department of Labor. (2013). Leading occupations. Retrieved from: https://www.dol.gov/wb/stats/leadoccupations.htm

RECEIVED 07/16/18 ACCEPTED 03/08/19 